\title{
PRÁTICAS SUSTENTÁVEIS: ADOÇÃO DE CULTURA INSTITUCIONAL EM IES
} SUSTAINABLE PRACTICES: ADOPTION OF INSTITUTIONAL CULTURE IN HEI

Recebido em 26.02.2019. Aprovado em 27.02.2019

Avaliado pelo sistema double blind review

Bruno Zeitoune

DOI: http://dx.doi.org/10.12712/rpca.v13i1.28165

brunozeitoune13@gmail.com

Departamento de Engenharia Civil/ Centro Federal de Educação Tecnológica Celso Suckow da Fonseca (CEFET/RJ) Rio de Janeiro - RJ, Brasil

ORCID: https://orcid.org/0000-0002-6985-0383

\section{Jose Aires Trigo}

jose.trigo09@gmail.com

Departamento de Gestão e Administração/ Universidade Estácio de Sá (UNESA) - Rio de Janeiro - RJ, Brasil ORCID: https://orcid.org/0000-0002-8382-3189

\author{
Aline Guimarães Monteiro Trigo \\ aline.trigo@,cefet-rj.br \\ Divisão de Estratégia para Sustentabilidade Ambiental Institucional (DISAI/DIGES) / Centro Federal de Educação \\ Tecnológica Celso Suckow da Fonseca (CEFET/RJ) - Rio de Janeiro - RJ, Brasil \\ ORCID: https://orcid.org/0000-0003-3639-8471
}

\section{Ursula Gomes Rosa Maruyama}

ursula.maruyama@,cefet-ri.br

Diretoria de Gestão Estratégica (DIGES)

Centro Federal de Educação Tecnológica Celso Suckow da Fonseca (CEFET/RJ)

ORCID: https://orcid.org/0000-0001-8350-229X

\section{Resumo}

As Instituições de Ensino Superior (IES) têm um papel relevante no despertar da consciência ambiental e formação de um pensamento crítico dos futuros profissionais, a fim de propiciar um ambiente adequado ao desenvolvimento de uma realidade sustentável e de que os alunos se constituam sujeitos coletivos e voltados à participação efetiva nos processos sociais. Nesse sentido, o presente estudo tem como objetivo demonstrar a importância do desenvolvimento de práticas e iniciativas sustentáveis nas Instituições de Ensino Superior, investigando a gestão com responsabilidade socioambiental, através de disciplinas e projetos, que tratem da temática da sustentabilidade dentro da instituição de ensino em questão. Ao incentivar projetos e práticas sustentáveis que colaborem com a educação ambiental, as IES poderão contribuir para a formação de um novo modelo de cultura institucional, que se baseia na mudança do comportamento de indivíduos de uma comunidade frente ao uso dos recursos ambientais. Palavras-chave: Práticas sustentáveis. A3P. Ensino Pesquisa e Extensão. IES.

\begin{abstract}
Higher Education Institutions (HEIs) play an important role in awakening environmental awareness and forming a critical thinking of future professionals, in order to provide an adequate environment for the development of a sustainable reality and for students to become collective subjects and effective participation in social processes. In this sense, the present study aims to demonstrate the importance of the development of sustainable practices and initiatives in Higher Education Institutions, investigating management with social and environmental responsibility, through disciplines and projects that deal with the sustainability theme within the educational institution in question. By encouraging sustainable projects and practices that collaborate with environmental education, HEIs can contribute to the formation of a new model of institutional culture, based on the change in the behavior of individuals in a community against the use of environmental resources.
\end{abstract}

Keywords: Sustainable Practices. A3P. Research and Extension Teaching. HEI. 


\section{Introdução}

Atualmente, é de reconhecimento global a necessidade da incorporação dos princípios e critérios sustentáveis dentro dos campi universitários. Por mais que esse fato já possa ser considerado um senso comum, é notável a dicotomia numa instituição de ensino superior (IES), sendo um dos principais ambientes de pesquisa e formação profissional ao mesmo tempo em que, os seus administradores ainda não se encontram em plena ressonância com a temática da sustentabilidade.

O campus compreende diversas atividades que dão suporte ao funcionamento da instituição - das administrativas às operacionais, que estão vinculadas as três dimensões do processo educativo - ensino, pesquisa e extensão, e que demandam recursos naturais, bem como geram resíduos e efluentes. Por conta disso, torna-se necessário conciliar o crescimento, a ampliação e a gestão das atividades de uma IES com critérios sociais e ambientais, de forma a reduzir desperdícios e impactos ambientais negativos possivelmente gerados.

Portanto, as Instituições de Ensino Superior (IES) têm um papel relevante na disseminação da sustentabilidade, especialmente ao incorporar valores sociais, ambientais e econômicos e princípios norteadores de estratégias ambientais, tanto nas disciplinas ensinadas quanto na administração de suas estruturas físicas (FERES \& ANTUNES, 2007). A comunidade dessas organizações deve aprender a pensar sobre sustentabilidade, e saber que suas atitudes influenciam em suas ações como cidadãos locais e globais (MOORE, 2005a) pró-ativos.

Sendo assim, o presente estudo tem como objetivo demonstrar a importância do desenvolvimento de práticas e iniciativas sustentáveis nas Instituições de Ensino Superior (IES), como uma estratégia para despertar a consciência ambiental e formação de um pensamento crítico, a fim de propiciar um ambiente adequado ao desenvolvimento de uma realidade sustentável e um novo modelo de cultura institucional, aonde os alunos se constituam sujeitos coletivos e voltados à participação efetiva nos processos sociais.

No decorrer do trabalho, serão tratadas as principais questões da consciência ambiental nas instituições de ensino que devem acompanhar à evolução dos aspectos da educação ambiental e sustentabilidade no mundo que afetam as IES. Um desses aspectos está ligado à política pública coordenada pelo MMA (2017a), que já foi implantada em mais de 300 órgãos públicos das três esferas, e nos mais diversos setores, principalmente em universidades. O Programa Agenda Ambiental na Administração Pública (A3P) é o principal programa de inclusão do tema da sustentabilidade nas atividades administrativas de órgãos públicos de todo país. O Centro Federal de Educação Tecnológica Celso Suckow da Fonseca (Cefet/RJ) recentemente (MMA, 2018) aderiu à A3P que insere às três dimensões do processo educativo e às atividades tradicionais da administração pública os elementos socioambientais dessa Agenda: uso dos recursos naturais e bens públicos; gestão de resíduos sólidos e efluentes gerados; contratações sustentáveis; qualidade de vida no ambiente de trabalho e de estudo; sensibilização e capacitação dos servidores; e obras públicas sustentáveis.

Com base nesses eixos temáticos, a pesquisa investiga a gestão com responsabilidade socioambiental, através de disciplinas (dimensão do ensino) e dos projetos (de extensão e de pesquisa) que tratem da temática ambiental e da sustentabilidade dentro da instituição de ensino em questão. Ao incentivar projetos e práticas sustentáveis que colaboram com a educação ambiental, as IES poderão contribuir para mudança no comportamento dos indivíduos de uma comunidade frente ao uso dos recursos ambientais e à geração de resíduos.

\section{Sustentabilidade e sua relação com a IES}

As Instituições de Ensino Superior (IES) como conhecemos hoje possuem um status estável na sociedade. Considerando essa estabilidade e a sua perspectiva de geração de resultados de longo prazo, pode-se concluir a importância dessa instituição para a sociedade. Com todo esse potencial positivo, as 
IES mostram-se, também, um agente essencial para a transformação social rumo à sustentabilidade (SCHOLZ et al., 2000; KEMP et al., 2007).

A instituição de ensino por si só já é conhecida por ser um dos principais fatores responsáveis pela formação do indivíduo como um cidadão. Essa formação também deve incluir as questões sociais e ambientais como seus pilares fundamentais. É através dessa educação que o indivíduo deve ser condicionado a se engajar nos desafios da sociedade contemporânea (TORMEY et al., 2008).

As IES possuem ainda a vantagem de reunir em seu ambiente, alunos, professores e funcionários que estão constantemente inseridos na realidade do ensino, das pesquisas e do engajamento social, o que configura a eles um grande potencial de se tornarem novos agentes de mudança. A organização também apresenta um potencial favorável para ser experimentada por aqueles que a frequentam, desenvolvendo em pequena escala, soluções criativas para as problemáticas estudadas (OWENS; HALFACREHITCHCOCK, 2006).

\section{Fatores disseminadores da sustentabilidade nas IES}

Muitos estudos revelam que a IES é um ambiente gerador do comportamento sustentável, considerando os seguintes aspectos influenciadores:

a) Utilizar um método educacional que não cumpra apenas com uma função informativa, mas que possua um teor preparatório para os desafios da sustentabilidade (STERLING, 2005);

b) Focar investimentos em pesquisas inter e multidisciplinares (VAN DAM, 2006);

c) Atuar em resoluções para as problemáticas sociais atuais e para as incertezas do futuro, e como lidar com essas questões (ADACHI et al., 2008);

d) Promover o compartilhamento de conhecimentos e recursos diversos (ADACHI et al., 2008);

e) Formação de líderes, com uma visão de longo prazo, responsáveis pela gestão da IES nesse período de transição (LOZANO, 2006).

A comunicação entre os agentes de uma IES é um fator que se mostra necessário, pois sua ausência inibe as ações voltadas para a sustentabilidade por tornar a equipe refém de reuniões internas, enquanto poderiam aproveitar esse tempo para se expressar para a comunidade local e agir de forma ativa com os projetos desenvolvidos (VELAZQUEZ et al., 2005; HERREMANS; ALLWRIGHT, 2000).

Sharp (2002) também explora o fator da comunicação, enfatizando o fortalecimento da relação interpessoal entre membros da universidade e a sociedade. Enquanto Jabbour (2010) trabalha a questão da inserção da consciência ambiental nas instituições de ensino, identificando agentes e definindo métricas para consolidação de uma cultura sustentável. Considerando esta abordagem, os agentes seriam representados pelos seguintes grupos:

a) Alunos, dos quais são responsáveis pelo desenvolvimento de pesquisas e de propostas de melhores práticas;

b) Futuros alunos, que veem as escolas alinhadas com os seus objetivos nas dimensões do processo educativo, desejando assim o ingresso nas tais;

c) Professores, servidores técnico-administrativos, empregados terceirizados e estudantes, responsáveis por analisar os prós e contras da gestão da instituição.

Como métricas, o autor propõe a inserção de disciplinas, voltadas à temática da sustentabilidade, obrigatórias, na matriz curricular do curso e uma constante análise do quanto que as atividades realizadas estão contribuindo para consciência ambiental dos agentes, visando um reconhecimento externo. 
Bacon et al. (2011) constatam que projetos interdisciplinares configuram-se como uma ferramenta pedagógica muito útil para demonstrar experiências práticas para os estudantes, apesar das dificuldades relacionadas à burocracia e falta de investimento humano e financeiro.

Moore (2005a) propõe, portanto, a inclusão de uma visão sustentável em todas as decisões da instituição de ensino, da integração da sustentabilidade nos planos de ensino à prática da multidisciplinaridade.

\section{A educação ambiental no ensino superior: uma abordagem interdisciplinar}

A Declaração de Estocolmo (1972) estabeleceu o primeiro momento em que se fez referência à inserção da sustentabilidade no ensino superior, destacando a necessidade de manter presente a educação ambiental na formação do indivíduo da escola primária até a idade adulta, de modo a incorporar o sentido da responsabilidade para a melhoria do ambiente nas pessoas, empresas e comunidades (MADEIRA, 2008).

Anos depois, a importância da pedagogia do desenvolvimento sustentável (ecopedagogia) foi lembrada na II Conferência das Nações Unidas sobre Meio Ambiente durante a Rio 92. A ecopedagogia incorpora a educação ambiental como um pressuposto e se desenvolve a partir de uma relação harmônica entre o homem e o ambiente, oferecendo estratégias, propostas e meios para o desenvolvimento sustentável (BENFICA, 2007). O capítulo da Agenda 21 intitulado "Educação, Formação e Consciência Pública" aponta o desenvolvimento de currículos transdisciplinares, a investigação científica referente à sustentabilidade e a formação de uma rede de organizações e pessoas envolvidas que promova a consciência ambiental como prioridades do ensino superior em torno da sustentabilidade (MADEIRA, 2008).

Em seguida, foi na Conferência Rio +20 (ONU, 2012) que foi produzido o documento "Desenvolvimento Sustentável e Educação" que firma o compromisso de incorporar as premissas do desenvolvimento sustentável no ensino, pesquisa e em suas próprias gestões e atividades organizacionais. Essa ação inspirou a criação da "Declaração para Instituições de Ensino Superior", objetivando nortear a iniciativa "Princípios para Educação e Gestão Responsável" (Principles for Responsible Management Education - PRME).

O documento supracitado discutiu a relevância da criação e manutenção de um currículo, que ensine e incentive a incorporação dos preceitos do desenvolvimento sustentável, além do fomento às pesquisas científicas que busquem o desenvolvimento, adaptação, difusão e transferência do conhecimento, dando especial destaque às pesquisas pautadas em tecnologias inovadoras. De forma complementar, ainda foram traçadas diretrizes para a incorporação de boas práticas nas operações diárias das atividades desenvolvidas nos campi. O cerne do documento sugere:

- reduzir a pegada ecológica através da energia, água e eficiência dos recursos materiais em nossos edifícios e instalações;

- a adoção de práticas de compras sustentáveis em nossas cadeias de fornecimento e serviços de catering;

- fornecendo opções de mobilidade sustentável para os alunos e professores;

- a adoção de programas eficazes para a minimização de resíduos, reciclagem e reutilização, e

promovendo estilos de vida mais sustentáveis (ONU, 2012, sem paginação).

Portanto, considera-se que uma IES sustentável é aquela que sensibiliza o aluno para as reais injustiças ao introduzir a problemática da degradação ambiental, ao mesmo tempo em que o estimula a buscar soluções tecnológicas e práticas ambientalmente sustentáveis (MADEIRA, 2008).

As políticas e ações regionais e locais a serem desenvolvidas exigem vários níveis de participação e compactuam com a necessidade de formulação de uma visão mais holística dos problemas do 
desenvolvimento, que foram propostos em uma Agenda desenvolvida por 193 Estados-Membros da ONU - a Agenda 2030 (ONUBR, 2015). Essa Agenda é um tipo de declaração que reúne 17 Objetivos Globais de Desenvolvimento Sustentável (ODS) - Quadro 1, visando abolir com a pobreza até 2030 e impulsionar universalmente o desenvolvimento econômico, o compromisso social e a conservação ambiental.

Quadro 1. Os 17 Objetivos Globais de Desenvolvimento Sustentável

\begin{tabular}{|l|l|}
\hline 1. Erradicação da Pobreza; & 9. Indústria, Inovação e Infraestrutura; \\
2. Fome Zero e Agricultura Familiar; & 10. Redução das Desigualdades; \\
3. Saúde e Bem-Estar; & 11. Cidades e Comunidades Sustentáveis; \\
4. Educação de Qualidade; & 12. Consumo e Produção Responsáveis; \\
5. Igualdade de Gênero; & 13. Ação contra a Mudança Global do Clima; \\
6. Agua Potável e Saneamento; & 14. Vida na Água; \\
7. Energia Limpa e Acessível; & 15. Vida Terrestre; \\
8. Trabalho Decente e Crescimento Econômico; & 16. Paz, Justiça e Instituições Eficazes; \\
& 17. Parcerias e Meios de Implementação. \\
\hline
\end{tabular}

Fonte: ONUBR (2015)

A inserção das premissas dos ODS nos campi universitários ainda é pouco conhecida da comunidade de uma instituição de ensino. Os avanços são necessários porque sua lógica reside no fato de as Instituições de Ensino Superior, em sua essência, serem espaços férteis para o surgimento de ideias, seguidos de experimentação e discussão (DISTERHEFT, 2011). Dessa forma, as IES se mostram estrategicamente ideais para atingir as metas de sustentabilidade, cumprindo com a abordagem global e a interdisciplinaridade demandada.

A educação ambiental fornece noções de ética ambiental na busca de um equilíbrio ecológico e qualidade de vida, colaborando assim na relação humano - meio ambiente (ZITZKE, 2002). Por isso, a necessidade de que a IES incentive o desenvolvimento de um projeto político-pedagógico que forme cidadãos conscientes da realidade socioambiental.

Sendo assim, a interdisciplinaridade para Zitzke não deve ser apresentada na forma de uma disciplina, mas sim como algo integrado aos valores e conceitos de cada assunto, que instigue uma conscientização e preocupação ambiental, devendo estar presente não apenas no ensino tradicional, mas também nas pesquisas e projetos de extensão. A despeito dessa integração, vale ressaltar os seguintes aspectos favoráveis:

- Uma reformulação do corpo docente, integrando questões sustentáveis aos conceitos formais das disciplinas. Junto a isso, uma mudança na postura dos docentes, tornando-os mais sintonizados com a nova política de sustentabilidade ambiental da instituição. Ao longo desse processo de integração, há uma tendência do docente em desenvolver um pensamento crítico, se tornando capaz de racionalizar problemas inerentes ao seu futuro campo de atuação, conseguindo então averiguar soluções para as questões ambientais (ARAÚJO, 2011). Por concentrar muitos alunos, a IES possui o potencial gerador de valores para um desenvolvimento sustentável. É na graduação que o aluno vivencia a sua formação profissional crítica e define o seu perfil profissional, e através desse processo, ele terá a questão ambiental como um fator essencial na escolha do ambiente de trabalho que quer atuar (CARLETTO et al., 2015).

- O encontro da pesquisa com a sustentabilidade. Através da pesquisa, é possível encontrar novos meios e técnicas para a solução de problemas rotineiros da sociedade. O mesmo deve acontecer para os problemas do meio ambiente. A partir desse método, os pesquisadores de iniciação científica e pós-graduação têm o desafio de conciliar a produção industrial elevada com as dimensões da sustentabilidade. Outro desafio a ser considerado é a necessidade de mudar a cultura de consumo imediatista vigente hoje, que 
também demanda a devida atenção das pesquisas realizadas e da IES, como sugerem Carletto et al. (2015). As pesquisas de desenvolvimento sustentável trazem ainda fundamentação teórica para a realização de projetos socioambientais na iniciativa públicoprivada.

- Os projetos de extensão, como agente de mudança, transformam as oportunidades em ações concretas de sustentabilidade. Esses projetos já são por definição ações de caráter educativo, social, cultural, científico e/ou tecnológico. Podem ser vinculados a um programa da IES ou projeto isolado. De qualquer forma, eles provocam impacto direto na comunidade em que a IES está inserida. A união do caráter ambiental com o socioeducativo é essencial para o desenvolvimento sustentável, segundo Jacobi (2003). Tal união pode resultar em ações de educação ambiental em escolas de ensino básico, em projetos de reciclagem, em palestras e debates sobre a questão ambiental, conscientização sobre o uso racional de recursos, etc. A extensão possui um caráter prático, ativo e dinâmico, agindo sempre em conjunto com a comunidade. Com tudo isso, a conscientização verde ganha mais força e a própria sociedade passa a fazer pressão para a realização de novos serviços que visem à redução dos danos ambientais; dessa forma possuindo então uma sociedade como agente transformador.

A partir desse processo, a IES é capaz de fomentar a conscientização da sociedade pelas questões ambientais e gerar a força de vontade necessária para buscar novas e boas práticas de desenvolvimento social e econômico, sem impactar de forma negativa o meio ambiente. Esse ativismo deixa de ser de exclusividade da IES e passa a ser também um movimento da sociedade sobre seu entorno.

\section{Desafios para implementação da sustentabilidade nas IES}

Um dos desafios relacionados à implementação da sustentabilidade nas IES é a incorporação desse tema na grade curricular. Ashford (2004) encontra obstáculos para essa inserção quando se refere aos cursos de engenharia. Mulder, Segalas e Ferrer-Balas (2012) estudaram alternativas para instigar o pensamento sustentável nesses profissionais e encontraram a resposta no pensamento de longo prazo, a fim de alcançar a sensibilização desse grupo para as questões socioambientais.

Stephens et al. (2008) enxergam cinco desafios e oportunidades para a implementação da sustentabilidade na IES. São eles:

a) Desafios dominantes da sustentabilidade na região;

b) Estrutura financeira e de independência da instituição;

c) Organização institucional;

d) Dimensão democrática do processo;

e) Interação e comunicação com a sociedade.

Para Lotz-Sisitka (2004), o principal desafio é clarear o significado de "mudança institucional", ratificando a importância da comunicação para consolidação desse processo de cultura sustentável.

Outros fatores levantados que dificultam esse processo são a falta de compromisso de membros da comunidade (MOORE et al., 2005b; EVANGELINOS; JONES, 2009), um processo de tomada de decisão inadequado, somado a problemas organizacionais (BARNES; JERMAN, 2002; MOORE et al., 2005b), a confusão na definição dos objetos da sustentabilidade (LEAL FILHO, 2000; VELAZQUEZ et al., 2005) e a limitação de verba (VELAZQUEZ et al., 2005). Como solução para todos esses aspectos, Evangelinos e Jones (2009) propõem a interação com o capital social que os gestores da IES estabelecem para o desenvolvimento sustentável, pois eles são determinantes para a facilitação das iniciativas propostas. 
Ainda assim, talvez a maior questão que permeia a inserção do pensamento sustentável na IES seja o desafio de trazer o aluno para uma realidade cada vez mais presente no mundo, devido aos problemas que distanciam a educação do ambiente. Tais problemas são os investimentos inadequados, a distância de atores importantes da sociedade e a dificuldade de formar cidadãos para o mundo de hoje.

\section{Metodologia}

Em toda pesquisa é importante definir os procedimentos metodológicos. Considerando os objetivos desta pesquisa, o presente trabalho é entendido como uma 'pesquisa exploratória', pois, sua finalidade é a de propiciar o maior leque possível de informações sobre o fenômeno estudado (CARRANCHO, 2005).

Quanto aos seus procedimentos, a estratégia a ser adotada é a de uma pesquisa documental, investigando as diferentes contribuições científicas sobre a temática da sustentabilidade nas dimensões do processo educativo no ensino superior. Sendo que o documento principal a ser estudado neste trabalho é o Plano de Trabalho institucional que deu origem à Agenda Ambiental na Administração Pública (A3P), que

[...] é uma política pública coordenada pelo Ministério do Meio Ambiente, devidamente testada e aprovada. A A3P já foi implantada em mais de 300 órgãos públicos das três instâncias, federal, estadual e municipal, e nos mais diversos setores - incluindo bancos, instituições judiciárias, militares e universidades. O Programa A3P é o principal programa de inclusão do tema da sustentabilidade nas atividades administrativas de órgãos públicos de todo país. O programa adiciona aos procedimentos tradicionais da administração pública os elementos socioambientais, exatamente aqueles que são exigidos pela modernidade, onde se busca economia, eficiência e sustentabilidade. (MMA, 2017a, p.9)

Segundo a Cartilha da Gestão Socioambiental nas Universidades (MMA, 2017b), são objetivos específicos do Programa A3P:

- Promover a economia de recursos naturais e a redução de gastos do erário público;

- Reduzir o impacto socioambiental negativo decorrente das atividades públicas;

- Promover a produção e o consumo de produtos e bens sustentáveis;

- Contribuir para a melhoria da qualidade de vida dos servidores e professores com práticas esportivas, música, canto, dança, artesanato e outras atividades;

- Sensibilizar e capacitar os servidores públicos para as questões socioambientais.

Os eixos temáticos ou linhas de atuação da A3P (Figura 1) nas IES públicas, que são: uso dos recursos naturais e bens públicos; gestão de resíduos sólidos e efluentes gerados; contratações sustentáveis; qualidade de vida no ambiente de trabalho e de estudo; sensibilização e capacitação dos servidores; e obras públicas sustentáveis, nortearão a pesquisa acerca da investigação da gestão com responsabilidade socioambiental, através de disciplinas (dimensão do ensino) e projetos (de extensão e de pesquisa) que tratem da temática ambiental e da sustentabilidade dentro da instituição de ensino em questão. O Centro Federal de Educação Tecnológica Celso Suckow da Fonseca - Cefet/RJ é o estudo de caso que permite ao investigador um amplo e detalhado conhecimento das características observadas no ensino e nos projetos. (GIL, 2012). 


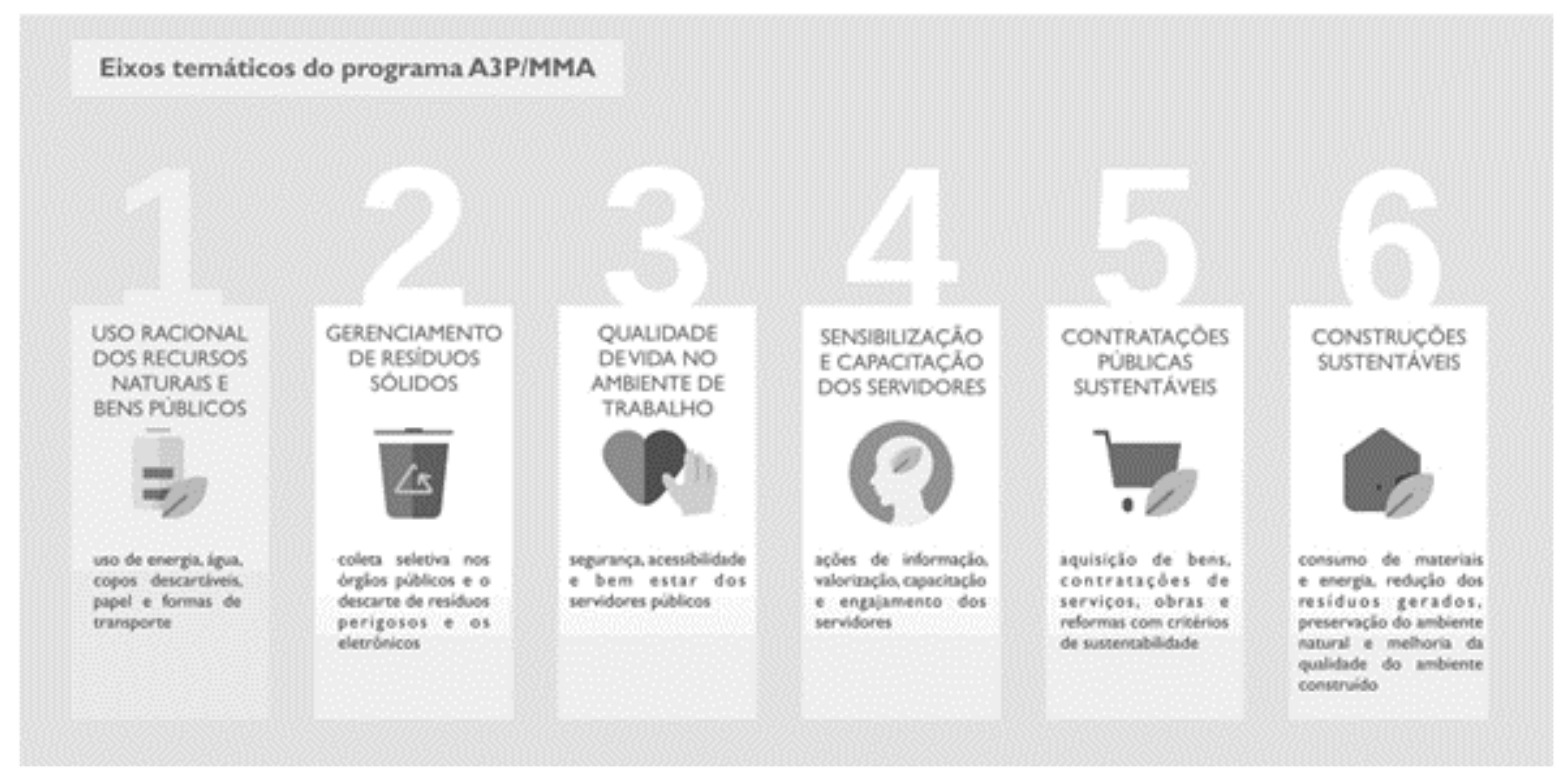

Figura 1. Eixos temáticos da A3P Fonte: MMA (2017b)

Desta forma, mais uma vez, se justificam os procedimentos de uma pesquisa documental, por ser mostrar uma fonte rica e estável de dados, não exigindo contato com os sujeitos da pesquisa, mas possibilitando uma leitura aprofundada das fontes, constituindo um suporte técnico relevante na pesquisa qualitativa, no sentido de completar ou desvelar novos aspectos sobre o tema proposto (GIL, 2012; LÜDKE e ANDRÉ, 1986).

\section{Estudo de Caso: Cefet/RJ}

O Centro Federal de Educação Tecnológica Celso Suckow da Fonseca (Cefet/RJ) é uma instituição autárquica de regime especial vinculada ao Ministério da Educação (MEC), criado pela Lei $n^{\circ} 6.545$, de 30 de junho de 1978. O Cefet/RJ tem por finalidade formar e qualificar profissionais no âmbito da educação tecnológica, bem como realizar pesquisa aplicada e promover o desenvolvimento tecnológico de novos processos, produtos e serviços, em estreita articulação com os setores produtivos e a sociedade, especialmente de abrangência local e regional, oferecendo mecanismos para a educação continuada.

A instituição conta com o campus-sede Maracanã, situado na cidade do Rio de Janeiro/RJ, emais sete campi espalhados pelo estado do Rio de Janeiro, que são: Angra dos Reis, Itaguaí, Maria da Graça, Nova Friburgo, Nova Iguaçu, Petrópolis e Valença. (CEFET/RJ, 2018)

Oferece cursos técnicos integrados ao ensino médio, subsequentes (pós-médio), tecnológicos, de graduação e de pós-graduação lato sensu e stricto sensu (mestrado e doutorado), nas modalidades presencial e a distância.

Conforme aponta o Projeto Pedagógico do Cefet/RJ (2010a), o ensino, pesquisa e extensão são indissociáveis, na medida em que:

- o ensino deve estar associado à extensão, em uma formação contextualizada nas questões sociais contemporâneas;

- o ensino junto à pesquisa aponta para o desenvolvimento de competências que visam introduzir os alunos a formas básicas de investigação, que, objetivando a geração de conhecimento, proverão subsídios para a própria atividade de ensino;

- a pesquisa, observando o contexto social, pode produzir ferramentas de intervenção, bem como a extensão pode atender àquelas realidades conhecidas via pesquisa. 
Dessa forma, a instituição de ensino deve estar comprometida com uma formação integral e cidadã a fim de alcançar um meio ambiente sustentável, de maneira que os alunos se constituam sujeitos coletivos, voltados à participação efetiva nos processos sociais.

Um primeiro passo já foi dado com a criação da Divisão de Estratégia para Sustentabilidade Ambiental Institucional, vinculada à Diretoria de Gestão Estratégica do Cefet/RJ (DISAI/DIGES), que busca transformar ideias em ações de gestão e educação ambiental, desenvolvendo em cada indivíduo da comunidade a percepção socioambiental, que envolva aspectos científicos, legais, ecológicos, econômicos, políticos, culturais e éticos. Destacam-se as competências da DISAI, que corroboram com os objetivos dessa pesquisa (CEFET/RJ, 2017, sem paginação)

I. estabelecer os parâmetros estratégicos para a sustentabilidade ambiental institucional;

II. coordenar a elaboração de uma Política Ambiental Institucional e seu cumprimento; $[\ldots]$

V. articular, orientar, acompanhar e avaliar projetos e programas voltados à gestão ambiental no âmbito institucional;

VI. garantir o acesso às informações sobre sustentabilidade ambiental e a participação democrática em todas as etapas de gestão ambiental;

VII. fomentar a integração das iniciativas institucionais relacionadas à sustentabilidade ambiental no âmbito do Ensino, da Pesquisa, da Extensão e da Gestão;

VIII. promover sistematicamente debate amplo e democrático sobre questões ambientais no Sistema Multicampi;

IX. organizar a estrutura de implantação da Agenda Ambiental da Administração Pública (A3P) no Cefet/RJ e orientar a sua implantação;

$[\ldots]$

A seguir, são apresentadas as principais iniciativas realizadas no Cefet/RJ na sua caminhada em direção a um futuro, que congregue todos os atores e as três dimensões do processo educativo - ensino, pesquisa e extensão, com intuito de propiciar um ambiente adequado ao desenvolvimento de uma realidade sustentável, em consonância com os eixos temáticos da Agenda Ambiental na Administração Pública (A3P) e atendimentos aos Objetivos Globais de Desenvolvimento Sustentável (ODS) e ao documento produzido durante a Rio + 20, "Desenvolvimento Sustentável e Educação".

\section{Ensino}

Considerando a finalidade do Cefet/RJ, exposta no art. $2^{\circ}$ do Projeto Pedagógico Institucional (PPI) o Ensino na instituição tem como características básicas:

I - oferta de educação tecnológica, levando em conta o avanço do conhecimento tecnológico e a incorporação crescente de novos métodos e processos de produção e distribuição de bens e serviços;

II - atuação prioritária na área tecnológica, nos diversos setores da economia;

III - conjugação, no ensino, da teoria com a prática;

IV - articulação verticalizada e integração da educação tecnológica aos diferentes níveis e modalidades de ensino, ao trabalho, à ciência e à tecnologia;

$\mathrm{V}$ - oferta de ensino superior de graduação e de pós-graduação na área tecnológica; VI - oferta de formação especializada em todos os níveis de ensino, levando em consideração as tendências do setor produtivo e do desenvolvimento tecnológico; VII - realização de pesquisas aplicadas e prestação de serviços;

VIII - desenvolvimento da atividade docente, abrangendo os diferentes níveis e modalidades de ensino, observada a qualificação exigida em cada caso;

IX - utilização compartilhada dos laboratórios e dos recursos humanos pelos diferentes níveis e modalidades de ensino;

$\mathrm{X}$ - desenvolvimento do processo educacional que favoreça, de modo permanente, a transformação do conhecimento em bens e serviços, em benefício da sociedade; 
XI - estrutura organizacional flexível, racional e adequada às suas peculiaridades e objetivos; XII - integração das ações educacionais com as expectativas da sociedade e as tendências do setor produtivo. (CEFET/RJ, 2010a).

A Educação Ambiental é de responsabilidade de todos, das escolas às universidades e de toda a comunidade onde o indivíduo se insere. Tornou-se um tema transversal, que estimula a adoção de uma postura participativa frente às questões relacionadas ao meio ambiente.

[...] propicia às pessoas uma compreensão crítica e global do meio ambiente. Chave para elucidar valores e desenvolver atitudes, que permitam adotar uma posição crítica e participativa frente às questões relacionadas com a conservação e a adequada utilização dos recursos naturais, com vistas à melhoria da qualidade de vida, a eliminação da pobreza extrema e do consumismo desenfreado. (BRASIL, 2002, p.103)

Nesse sentido, é de fundamental importância que a IES tenha em todos os cursos de graduação das áreas de ciências da saúde, ciências exatas, ciências agrárias, ciências humanas, ciências sociais, ciências biológicas e ciências tecnológicas, disciplinas que tratem da temática ambiental e sustentabilidade.

A A3P entende que a sociedade necessita de profissionais, formados nas IES, de diferentes áreas com uma postura crítica e participativa e com conhecimento em meio ambiente, sustentabilidade e responsabilidade socioambiental, o que fará a diferença no mercado de trabalho e nos cuidados que ele terá diante dos desafios para preservação do planeta e melhoria da qualidade de vida. (MMA, 2017a)

No Cefet/RJ, observa-se a presença de uma disciplina comum - Ciências Ambientais - em todos os cursos de graduação, que investiga a problemática ambiental e discute as soluções/ instrumentos de gestão ambiental dentro do contexto de cada curso de graduação. A abordagem é feita por meio de aula expositiva, de desenvolvimento de projetos ambientais e com apresentação de estudos de casos voltados para a questão ambiental. Por exemplo, no curso de Bacharelado em Ciências da Computação, destacamse os seguintes objetivos da disciplina Ciências Ambientais:

\section{Objetivo Geral:}

- Habilitar o aluno a compreender como a temática ambiental encontra-se envolvida e inserida nos processos das Ciências da Computação.

Objetivos Específicos:

- Entender os conceitos básicos sobre o Meio Ambiente;

- Reconhecer o Homem como um dos atores pertencentes ao Meio - Ambiente e compreender a sua ação modificadora dos ambientes naturais;

- Reconhecer os aspectos da sustentabilidade sobre os projetos;

- Identificar os principais instrumentos legais na área ambiental;

- Obter uma visão geral dos instrumentos de Gestão Ambiental Pública e Privada;

(CEFET/RJ, 2010a)

A disciplina é uma oportunidade de discutir a relevância da Educação Ambiental no currículo do curso, aproximando o aluno e a comunidade no qual está inserido, de propostas e práticas sustentáveis, a partir do planejamento, execução e discussão dos prós e contras das mesmas, e que podem ser desenvolvidas, na prática, através dos projetos de extensão e de pesquisa. Deve-se buscar não apenas nessa disciplina, mas em outras já existentes o desenvolvimento e o reforço de conteúdos acadêmicos que enfatizem a formação social, ambiental, cultural, humanística e cidadã.

O Cefet/RJ oferece cursos técnicos integrados ao ensino médio e não se observa a temática da sustentabilidade na forma de uma disciplina, mas sim integrada aos valores e as premissas sustentáveis para o desenvolvimento de pesquisas e de projetos de extensão, que estimulam a conscientização e a preocupação ambiental dos corpos discente e docente. 


\section{Pesquisa}

A atividade de pesquisa do Cefet/RJ é gerenciada pelo Departamento de Pesquisa (DEPEQ), de caráter sistêmico, que está subordinado à Diretoria de Pesquisa e Pós-Graduação, tendo como finalidade incentivar, sistematizar, cadastrar, gerir e avaliar a atividade de pesquisa realizada na instituição, em todos os níveis de ensino. As ações do Departamento se concretizam através da Coordenadoria de Pesquisa e Estudos Tecnológicos (COPET), que estimula a realização de atividades de pesquisa científica (nos cursos de graduação) e tecnológica (nos cursos técnicos integrados ao ensino médio) no Cefet/RJ. (CEFET/RJ, 2010a)

A pesquisa também tem suas atividades estruturadas através dos Grupos de Pesquisa do Cefet/RJ cadastrados no Diretório de Grupos do CNPq (CEFET/RJ, 2010a), destacando-se alguns dentro da temática da sustentabilidade, a saber.

- Meio Ambiente e Eficiência Energética,

- Gestão do Conhecimento e da Inovação Tecnológica,

- CTS e Educação,

- Empreendedorismo, Energia, Meio Ambiente e Tecnologia e

- Nanociência e Meio Ambiente.

Embora grande parte da publicação científica da instituição esteja voltada para a área tecnológica, demonstra-se, por meio de projetos, a contribuição que a pesquisa traz para o desenvolvimento socioeconômico do país, despertando a vocação científica na formação dos futuros pesquisadores.

No período de 2015 a 2017, destaca-se o aumento de projetos de pesquisa pautados no desenvolvimento sustentável, orientados por professores do Centro com experiência e especialização na área e cuja participação discente vem aumentando. O gráfico 1 revela o panorama da pesquisa nos campi do Cefet/RJ, ressaltando os projetos de pós-graduação relacionados à conservação e eficiência de energia elétrica, que estão vinculados à temática da A3P "Uso de recursos naturais e bens púbicos" e os projetos de educação ambiental associados à temática da A3P "Sensibilização e capacitação" (DIPPG CEFET/RJ, 2018).

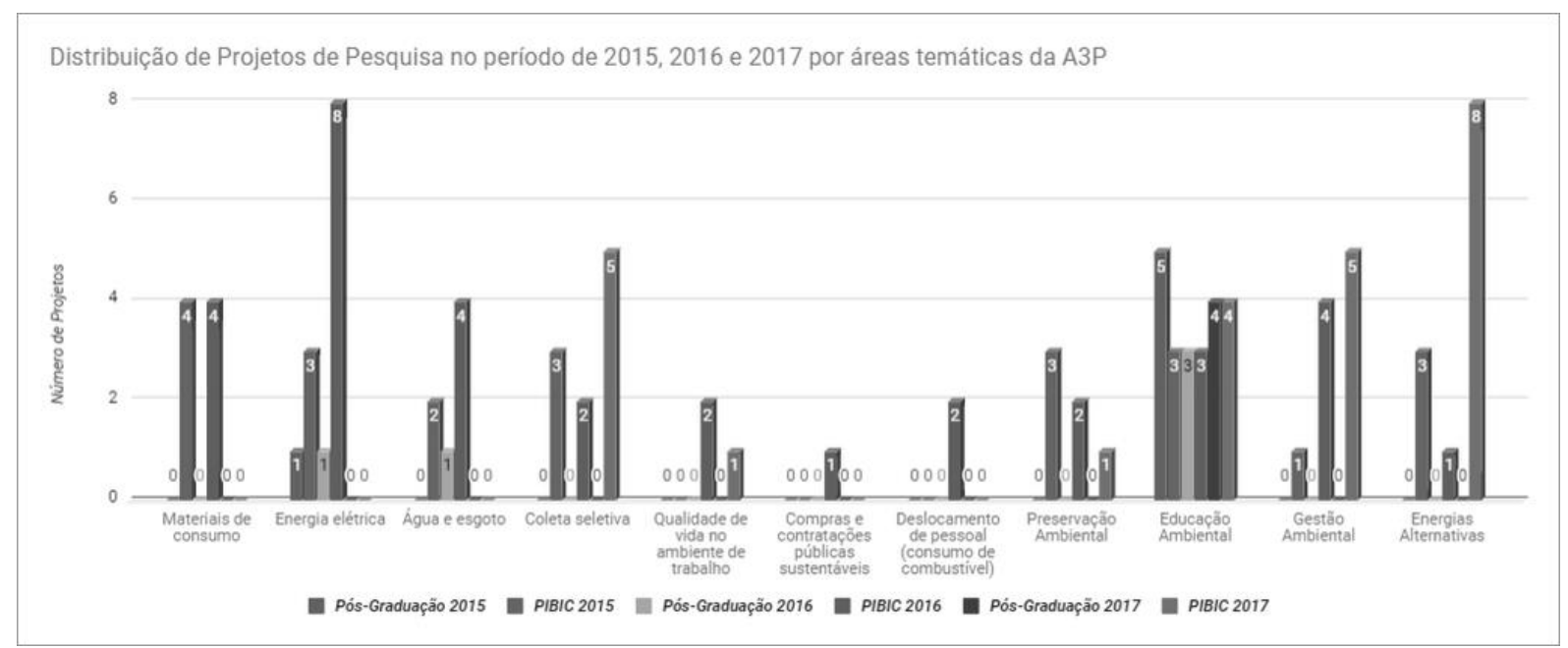

Gráfico 1 . Panorama da Pesquisa no Cefet/RJ no período de 2015 a 2017 Fonte: Elaboração própria a partir de DIPPG CEFET/RJ (2018)

Enquanto que nos Programas de Iniciação Científica e tecnológica (PIBIC), cabe ressaltar, além das temáticas supracitadas, a Coleta Seletiva e a Gestão Ambiental como temas também desenvolvidos nos projetos submetidos e aprovados. 
Subordinado a Diretoria de Pesquisa e Pós-graduação, encontra o Núcleo de Inovação Tecnológica (NIT), que tem o objetivo de gerir a política institucional de estímulo à inovação e outras formas de transferência tecnológica, bem como da governança do sistema de inovação do Cefet/RJ. (CEFET/RJ, 2010b)

\section{Extensão}

As atividades de extensão desenvolvidas no Centro são diferenciadas, em virtude de sua origem e natureza no campo da educação tecnológica. Essa atuação se concretiza em programas, projetos e cursos, produção tecnológica e publicação, utilizando recursos materiais e financeiros próprios, além de prestação de serviços (CEFET/RJ, 2010b).

Ações oriundas do protagonismo estudantil conduziram a programas tais como: o CEFET Jr. Consultoria, que coloca o conhecimento científico-tecnológico adquirido, individual e coletivamente, a serviço do desenvolvimento político, econômico e social do espaço em que vivem; o programa Enactus Cefet/RJ, que fomenta o desenvolvimento da ciência e da tecnologia no sentido da perspectiva da promoção humana e o Programa Turma Cidadã, que incentiva a participação em movimentos sociais (CEFET/RJ, 2010b).

Durante o ano de 2017, os servidores do Centro participaram de ações/ eventos, coordenados pela DISAI/DIGES, para promoção de uma cultura de gestão e responsabilidade socioambiental e valorização do meio ambiente institucional. Os eventos de extensão, certificados pela Diretoria de Extensão do Cefet/RJ (DIREX), ficaram conhecidos como "Rodas de Conversa de Sustentabilidade Ambiental Institucional". A primeira ocorrida em 28 de junho teve por objetivo expor e ouvir ideias e propostas a serem desenvolvidas para atendimento à Agenda Ambiental na Administração Pública (A3P). A segunda, mais específica, ocorrida em 29 de novembro teve por objetivo expor, ouvir e compartilhar ideias e propostas de uso racional de água, a partir do diagnóstico de consumo de água realizado no campus Maracanã.

As duas ações supracitadas contribuíram para o atendimento aos eixos temáticos da A3P (Uso de recursos naturais e bens públicos, gestão adequada dos resíduos, qualidade de vida no ambiente de trabalho, sensibilização $e$ capacitação dos servidores e licitações sustentáveis), desenvolvidas e aplicadas na coletividade, com apoio da Alta Administração do Centro. E no mês de junho do ano de 2018, celebrando o Dia do Meio Ambiente, houve uma palestra no Cefet/RJ no campus Maracanã sobre Sustentabilidade, Inovação e Empreendedorismo com uma pesquisadora especializada na área de inovação em modelos de negócios e referência em sustentabilidade. Esse evento contribuiu para a sensibilização da comunidade, voltada para temática da sustentabilidade.

No tocante aos projetos de extensão desenvolvidos junto ao Departamento de Extensão e Assuntos Comunitários, vinculado à DIREX, que têm "estimulado a ação extensionista tanto no âmbito interno, envolvendo alunos e servidores, como no âmbito externo, com a presença e participação da comunidade dos municípios e localidades" (DEAC CEFET/RJ, 2018a), destacou-se no período de 2015 a 2018 os projetos relacionados ao desenvolvimento de ações para a promoção humana e melhoria da qualidade de vida, que conduzam a sustentabilidade do ambiente interno e externo do Centro (Gráfico 2). 


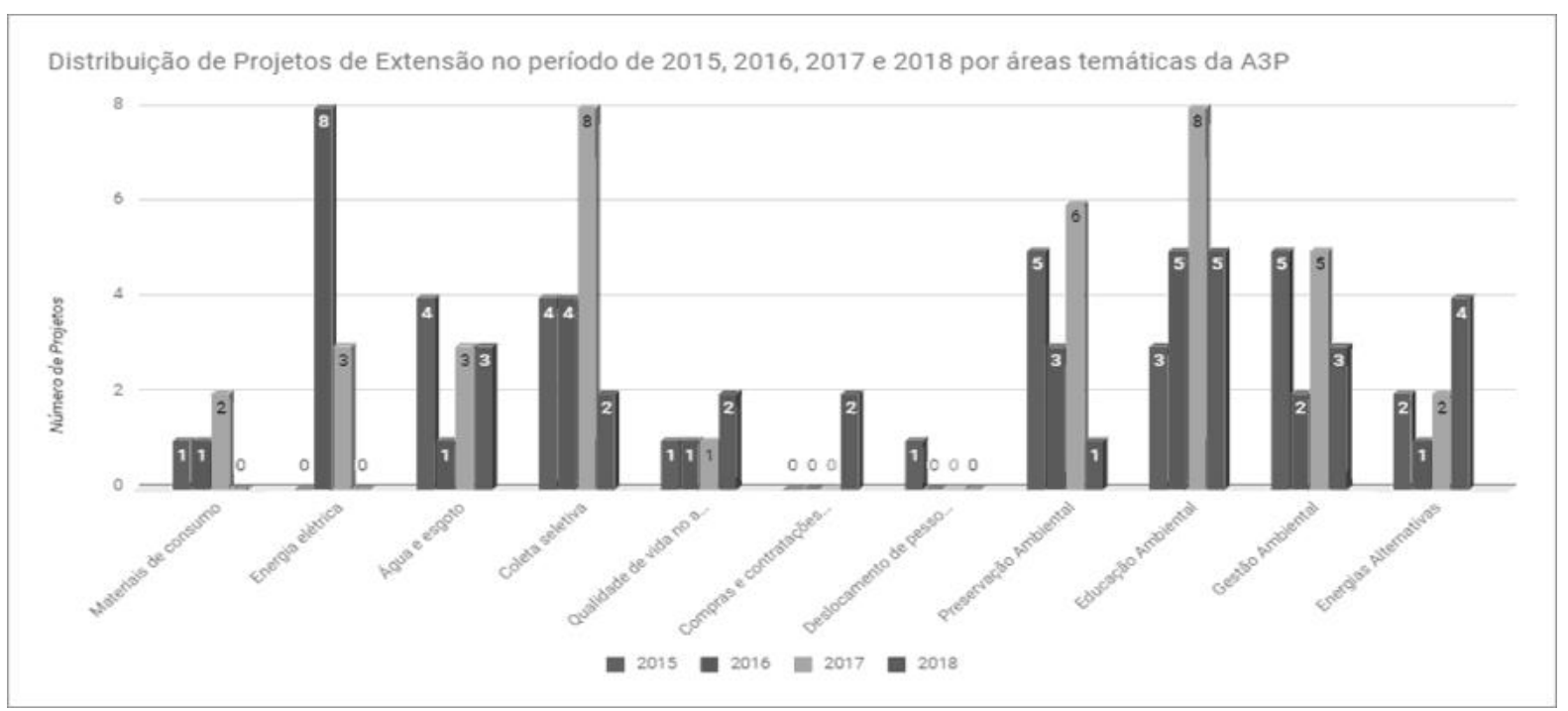

Gráfico 2 . Panorama da Extensão no Cefet/RJ no período de 2015 a 2018 Fonte: Elaboração própria a partir de DEAC CEFET/RJ (2018b)

O gráfico 2 revela o panorama da extensão nos campi do Cefet/RJ, ressaltando os projetos de educação e de preservação ambiental associados à temática da A3P "Sensibilização e capacitação"; de coleta seletiva, que estão relacionados à temática da A3P "Gestão adequada de resíduos" e de energia elétrica e energias alternativas, que estão vinculados à temática da A3P "Uso de recursos naturais e bens públicos" (DEAC CEFET/RJ, 2018b).

Por estar envolvido diretamente com a sociedade e com a formação de cidadãos profissionais capazes de colocar o conhecimento tecnológico a serviço do desenvolvimento político, econômico e social do espaço em que vivem, o Centro apresenta outros programas de gestão já estruturados, tais como o Programa Recicla Cefet/RJ, iniciado em 2015, no campus Maracanã e, atualmente, ampliado para as demais unidades descentralizadas do Cefet/RJ.

O Programa, por meio de uma Comissão de Coleta Seletiva Solidária, institui a separação e destinação de resíduos sólidos recicláveis descartados pela instituição de ensino para cooperativa/ associação de catadores, seguido de sensibilização de alunos, servidores e funcionários da limpeza, de acordo com o Decreto 5.940/2006.

\section{Considerações finais}

A articulação entre a pesquisa, o ensino e a extensão tem como função não somente a produção do conhecimento acadêmico, mas a formação de indivíduos críticos e conscientes da realidade de que fazem parte. Além das atividades próprias da formação acadêmica vêm sendo incentivadas outras que tenham por fim promover a participação estudantil em iniciativas em prol da cidadania e da responsabilidade socioambiental.

De fato, é providencial que as três dimensões que envolvam o processo educativo - ensino, pesquisa e extensão - no Centro estejam em consonância com os seis pontos fundamentais da sustentabilidade instituídos pelo MEC (2017), no sentido de promover a conscientização pública para a preservação do meio ambiente.

- Promoção do enfoque da sustentabilidade em seus múltiplos aspectos, por meio de atividade curricular/disciplina/projetos interdisciplinares obrigatórios que promovam o estudo da legislação ambiental e conhecimentos sobre gestão ambiental, de acordo com os cursos de bacharelado, tecnologia, especialização e extensão das instituições públicas e privadas de nível superior voltadas para a formação de profissionais que atuam nas diferentes áreas. 
- Fomento a pesquisas voltadas à construção de instrumentos, metodologias e processos para a abordagem da dimensão ambiental que possam ser aplicados aos currículos integrados dos diferentes níveis e modalidades de ensino.

- Acompanhamento avaliativo da incorporação da dimensão ambiental na educação superior de modo a subsidiar o aprimoramento dos projetos pedagógicos e a elaboração de diretrizes específicas para cada um de seus âmbitos.

- Fomento e estímulo à pesquisa e extensão nas temáticas relacionadas à educação ambiental.

- Incentivo à promoção de materiais educacionais que sirvam de referência para a educação ambiental nos diversos níveis de ensino e modalidades de ensino e aprendizagem.

- Participação em processos de formação continuada e em serviço de docentes (MEC, 2017, p. 22).

A disciplina Ciências Ambientais, observada nos cursos de graduação, reconhece a inserção dos preceitos do desenvolvimento sustentável, quando realiza a apresentação dos instrumentos de gestão e educação ambiental ao corpo discente, com a finalidade de reduzir desperdícios e fazer pensar em projetos inovadores sustentáveis.

O desenvolvimento de uma aula, que versa sobre um tema transversal que é influente no processo educativo de uma IES, deve encorajar o docente a não apenas realizar mudanças nos planos de ensino e de curso, mas transformar a forma de ensinar. Pensar em um método mais contextualizado pelas problemáticas ambientais vivenciadas, que interferem no processo educativo, e mais adequado às demandas do mercado de trabalho, visando à formação da vida profissional associada à responsabilidade socioambiental.

Cabe destacar também o crescimento dos projetos de extensão e de pesquisa, ao longo do período em comum investigado no Cefet/RJ, atendendo a maioria dos eixos temáticos da A3P: uso dos recursos naturais e bens públicos, gestão de resíduos sólidos e efluentes gerados, sensibilização e capacitação dos servidores e qualidade de vida no ambiente de trabalho e de estudo e aos preceitos do documento "Desenvolvimento Sustentável e Educação".

A pesquisa na instituição, que é observada nos projetos de pós-graduação e de iniciação científica e tecnológica, demonstra o desenvolvimento de técnicas e meios para a resolução dos problemas ambientais, ressaltando um amadurecimento da comunidade e reconhecimento interno e externo dos trabalhos/ artigos, que são apresentados. A extensão vem trazendo um impacto positivo à comunidade, em função da praticidade e dinâmica na disseminação do conhecimento gerado em pesquisa com a temática da sustentabilidade aplicada em projetos, além daqueles já desenvolvidos pelos grupos de extensão consolidados e estruturados no Centro.

A visão holística, que é desejável para a resolução dos problemas ambientais suscitados em aulas e para as experiências vivenciadas em projetos, é percebida e desenvolvida no corpo discente, por meio da orientação do corpo docente e demais servidores, que se encontram sintonizados com a política de sustentabilidade ambiental institucional. É consenso que a discussão da sustentabilidade não deve se restringir somente ao ambiente acadêmico e sim incluir o mercado de trabalho. Deve-se integrar o processo educativo às ideias, dando oportunidade para a prática e a pesquisa. Sabe-se que projetos englobando os preceitos da sustentabilidade devem estar alinhados à necessidade cada vez maior da preservação dos recursos naturais, à qualidade de vida do homem e ao desenvolvimento econômico do país.

Esta pesquisa é uma oportunidade de demonstrar a relevância da Educação Ambiental na formação acadêmica e conhecimento junto aos alunos, mas também a comunidade do qual o aluno participa. Nesse sentido, busca-se alcançar a conscientização da sociedade pelas questões ambientais e fomentar novas 
práticas de desenvolvimento social e econômico, sem impactar de forma negativa o meio ambiente. Essa atitude em prol da sustentabilidade deixa de ser de exclusividade da IES e passa a ser também um movimento da sociedade sobre o entorno.

O trabalho, comparativamente a outro estudo (GAZONI et. al., 2018), demonstrou que o Centro vem fomentando o desenvolvimento de boas práticas e projetos inovadores, no que tange o relacionamento entre a IES e o desenvolvimento sustentável, com intuito de colaborar na incorporação de princípios e objetivos disseminados pelo Centro, que podem ser observados na política de sustentabilidade ambiental do Cefet/RJ (CEFET/RJ, 2018b). Ainda assim, obstáculos permeiam a inserção do pensamento sustentável na IES: seja o desafio de trazer o aluno para uma realidade cada vez mais presente no mundo, devido aos problemas que distanciam a educação do ambiente e aos investimentos inadequados.

\section{Referências}

ADACHI, T.; HIRAKI, Y.; YAMAMOTO, K.; TAKAHASHI, Y.; FUKUNISHI, H.; HSU, R-R.; SU, H-T.; CHEN, A. B.; MENDE, S. B.; FREY, H. U.; LEE, L. C. Electric fields and electron energies in sprites and temporal evolutions of lightning charge moment measurements. Journal of Physcs, v. 41, n. 23, 2008.

ARAUJO, B.S. A importância da educação ambiental para a efetividade da Política Nacional do Meio Ambiente. In: BENJAMIN, A.H.; IRIGARAY, C.T.; LECEY, E.; CAPELLI, S. (Org.). PNMA: 30 anos da Política Nacional de Meio Ambiente. São Paulo: Imprensa Oficial do Estado de São Paulo, 2011.

ASHFORD, N.A. Major challenges to engineering education for sustainable development. International Journal of Sustainability in Higher Education, v. 5 n. 3, p. 239- 50, 2004.

BACON, C. M.; MULVANEY, D.; BALL, T. B.; DUPUIS, E. M.; GLIESSMAN, S. R.; LIPSCHUTZ, R. D.; SHAKOURI, A. The creation of an integrated sustainability curriculum and student praxis projects. International Journal of Sustainability in Higher Education, v. 12, n. 2, p. 193-208, 2011.

BARNES, P.; JERMAN, P. Developing an environmental management system for a multiple-university consortium. Journal of Cleaner Production, v. 10, p. 33-9, 2002.

BENFICA, G. Sustentabilidade e Educação. Revista Virtual de Letras e Cultura, Salvador, n., p.1-9, 2007. Disponível em: < http://www.uneb.br/sumario/professores/gregoriobenfica.pdf >Acesso em: 5 de maio de 2017.

BRASIL. Ministério do Planejamento, Orçamento e Gestão. Secretaria de Orçamento Federal. Orçamentos da união exercício financeiro 2003: Projeto de lei orçamentária. - Brasília: MP, SOF, 2002.

BRASIL. Decreto 5.940, de 25 de outubro de 2006. Institui a separação dos resíduos recicláveis descartados pelos órgãos e entidades da administração pública federal direta e indireta, na fonte geradora, e a sua destinação às associações e cooperativas dos catadores de materiais recicláveis, e dá outras providências. Diário Oficial da União, Brasília, 26/10/2006. Disponível em: < http://www.planalto.gov.br/ccivil_03/_ato2004-2006/2006/decreto/d5940.htm> Acesso em 5 mai. 2018.

CARLETTO, D. L. ; SILVA, M. P. ; GUERRA, A. F. S. A abordagem fenomenológica na investigação da percepção de professores sobre o ambiente estuarino da Baía da Babitonga, Santa Catarina, Brasil: contribuição do Programa de Educação Ambiental do Projeto Toninhas/Univille. Ambientalmente Sustentable, v. II, p. 357-374, 2015. 
CARRANCHO, A. Metodologia da Pesquisa Aplicada à Educação. Rio de Janeiro: CCAA Editora, 2005.

CEFET/RJ. Projeto Pedagógico Institucional - PPI. Rio de Janeiro, 2010a. Disponível em: http://livrozilla.com/doc/1165546/ppi---cefet-rj Acesso em 01 fev. 2018.

CEFET/RJ. Plano de Desenvolvimento Institucional - PDI. Rio de Janeiro, 2010b. Disponível em: $<$ https://slidex.tips/download/cefet-rj-centro-federal-de-educaao-tecnologica-celso-suckow-dafonseca-plano-de> Acesso em 02 fev. 2018.

CEFET/RJ. Regimento Interno da DIGES. Ministério da Educação e Cultura. Centro Federal de Educação Tecnológica Celso Suckow da Fonseca - CEFET/RJ. 2017

CEFET/RJ. Relatório de Gestão do Exercício de 2017. Diretoria de Gestão Estratégica. Rio de Janeiro, 2018a.

CEFET/RJ. Política de Sustentabilidade Ambiental do CEFET/RJ. Conselho Diretor. Centro Federal de Educação Tecnológica Celso Suckow da Fonseca - CEFET/RJ. 2018b. Disponível em: < http://www.cefet-rj.br/attachments/article/3389/Resolu\%C3\%A7\%C3\%A3o\%20044-

2018\%20Pol\%C3\%ADtica\%20de\%20Sustentabilidade.pdf> Acesso em 02 mar. 2019

DEAC CEFET/RJ - Departamento de Extensão e Assuntos Comunitários - Centro Federal de Educação Tecnológica Celso Suckow da Fonseca. PBEXT 2018. Rio de Janeiro: CEFET-RJ, 2018 a. Disponível em: < http://www.cefet-rj.br/index.php/acoes-de-extensao> Acesso em 4 jul. 2018

DEAC CEFET/RJ - Departamento de Extensão e Assuntos Comunitários - Centro Federal de Educação Tecnológica Celso Suckow da Fonseca. Livro Semana de Extensão 2015. 2016. 2017. 2018. Rio de Janeiro: CEFET-RJ, 2018b. Disponível em: < http://www.cefet-rj.br/index.php/acoes-deextensao> Acesso em 5 jul. 2018.

DIPPG CEFET/RJ - Diretoria de Pesquisa e Pós-Graduação - Centro Federal de Educação Tecnológica Celso Suckow da Fonseca. Programa PIBIC Seminário Anual. Livros de Resumos 2015. 2016. 2017. Rio de Janeiro: CEFET-RJ, 2018. Disponível em: < http://dippg.cefet-rj.br/pibic/seminarioanual.php> Acesso em 2 jun. 2018.

DISTERHEFT, A. Sustainability at the Campus Environmental Management Systems (EMS) implementation processes and practices at European Higher Education Institutions Top-down versus Participatory Approaches. Dissertação (Mestrado em Cidadania Ambiental e Participação). Universidade Aberta. Lisboa: Universidade Aberta, 2011. Disponível em: < https://repositorioaberto.uab.pt/bitstream/10400.2/1870/1/Antje\%20Disterheft $\% 20$ -

\%20tese\%20mestrado\%20MCAP\%202009-11\%20Sustainability.pdf> Acesso em 5 jul. 2018.

EVANGELINOS, K. I.; JONES, N. An analysis of social capital and environmental management of higher education institutions. International Journal of Sustainability in Higher Education, v. 10, n. 4, p. 334-342, 2009.

FERES, Y. N.; ANTUNES, F. Z. Gestão ambiental em instituições de ensino: programa eco eficiência e sistema de gestão ambiental do SENAC São Paulo. IX ENGEMA, Encontro Nacional sobre Gestão Empresarial e Meio Ambiente. Curitiba, 2007. Disponível em <http://www.engema.up.edu.br/arquivos/engema/pdf/PAP0337.pdf> Acesso em: 20 mar. 2017.

GAZONI, F.; SCHERER, F.L.; HAHN, I.S.; CARPES, A.M.; SANTOS, M.B. O Papel das IES no Desenvolvimento Sustentável: Estudo de Caso da Universidade Federal de Santa Maria.Revista Gestão Universitária na América Latina Revista GUAL, Florianópolis, v.11, n.1, p.48-70, janeiro 2018. 
Disponível em: < file://C:/Users/Aline/Downloads/43192-182213-2-PB.pdf> Acesso em 5 mar. 2019.

GIL, Antonio Carlos. Métodos e técnicas de pesquisa social. $7^{a}$ edição. São Paulo: Atlas, 2012.

HERREMANS, I.; ALLWRIGHT, D. Environmental management systems at North American universities: what drives good performance? International Journal of Sustainability in Higher Education, v. 1 n. 2, p. 179, 2000.

JABBOUR, C. J. C. Greening of business schools: a systemic view. International Journal of Sustainability in Higher Education, v. 11, n.1, p. 49-60, 2010.

JACOBI, Pedro. Educação Ambiental, Cidadania e Sustentabilidade. Cadernos de Pesquisa, n. 118, p. 189-205, março, 2003.

KEMP, R., LOORBACH, D.; ROTMANS; J. Transition management as a model for managing processes of co-evolution towards sustainable development. The International Journal of Sustainable Development and World Ecology, v. 14, n. 1, p. 78-91, 2007.

LEAL FILHO, W. Dealing with misconceptions on the concept of sustainability. International Journal of Sustainability in Higher Education, v. 1, n. 1, p. 9-19, 2000.

LOTZ-SISITKA, H. Stores of Transformation. International Journal of Sustainability in Higher Education, v. 5, n. 1, p. 8-10, 2004.

LOZANO, R. Incorporation and institutionalization of SD into universities: breaking through barriers to change. Journal of Cleaner Production, v. 14, n. 9-11, p. 787-96, 2006.

LUDKE, M.; ANDRÉ, M.E.D.A. Pesquisa em educação: abordagens qualitativas. São Paulo: EPU, 1986.

MADEIRA, A. C. F. D. Indicadores de sustentabilidade para instituições de ensino superior. Dissertação (Mestrado em Engenharia do Ambiente) - Faculdade de Engenharia da Universidade do Porto, Porto, 2008.

MEC - MINISTÉRIO DE EDUCAÇÃO. Portaria 3.796, de 1 de novembro de 2005, que aprova o Estatuto do Centro Federal de Educação Tecnológica Celso Suckow da Fonseca - RJ.

MEC - MINISTÉRIO DA EDUCAÇÃO. Proposta de Diretrizes Curriculares Nacionais para a Educação Ambiental. $2017 . \quad$ Disponível em: $<$ http://portal.mec.gov.br/dmdocuments/publicacao13.pdf > Acesso em: 29 mar. 2017.

MMA - MINISTÉRIO DO MEIO AMBIENTE. Secretaria de Articulação Institucional e Cidadania Ambiental. A3P. Agenda Ambiental na Administração Pública. 5 Edição. Brasília. 2017a. Disponível em: <http://www.mma.gov.br/responsabilidade-socioambiental/a3p/ > Acesso em 25 mai. 2017.

MMA - MINISTÉRIO DO MEIO AMBIENTE. Gestão socioambiental nas universidades públicas: A3P / Ministério do Meio Ambiente, Secretaria de Articulação Institucional e Cidadania Ambiental, Departamento de Proteção e Consumo Sustentáveis, Programa Ambiental na Administração Pública. - Brasília, DF: MMA, 2017b.

MMA - MINISTÉRIO DO MEIO AMBIENTE. Extrato de Adesões. Agenda Ambiental na Administração Pública (A3P). Diário Oficial da União. Seção 3. N. 19. 26 de Janeiro de 2018. p. 95.

MOORE, J. Barriers and pathways to creating sustainability education programs: Policy rhetoric and reality. Environmental Education and Research, 11(5), 537-555, 2005a. 
MOORE, J.; PAGANI, F.; QUAYLE, M.; ROBINSON, J.; SAWADA, B.; SPIEGELMAN, G.; WYNSBERGHE, R.W. Recreating the university from within: collaborative reflections on the University of British Columbia's engagement with sustainability. International Journal of Sustainability in Higher Education, v. 6, n. 1, p. 65-80, 2005b.

MPOG - MINISTÉRIO DO PLANEJAMENTO, ORCAMENTO E GESTÃO. Instrução Normativa 10, de 14 de novembro de 2012. Estabelece regras para elaboração dos Planos de Gestão de Logística Sustentável de que trata o art. 16, do Decreto n 7.746, de 5 de junho de 2012, e dá outras providências. Publicada no Diário Oficial da União, Brasília, de 14/11/2012. Disponível em: < http://www.lex.com.br/legis_23960118_INSTRUCAO_NORMATIVA_N_10_DE_12_ > Acesso em: 29 set. 2017.

MULDER, K; SEGALAS, J.; FERRER-BALAS, D. How to educate engineers for/in sustainable development. Ten years of discussion, remaining challenges. International Journal of Sustainability in Higher Education, v. 13, n. 3, p. 211-218, 2012.

ONU - ORGANIZAÇÃO DAS NAÇÕES UNIDAS. Os resultados da Rio + 20. Não paginado, 2012. Disponível em: <http://www.onu.org.br/rio20/tema/desenvolvimento-sustentavel/> Acesso em: 18 ago. 2017.

ONUBR - Nações Unidas no Brasil. Centro de Informação das Nações Unidas para o Brasil (UNIC Rio). Transformando Nosso Mundo: A Agenda 2030 para o Desenvolvimento Sustentável. Outubro de 2015. Disponível em: < https://nacoesunidas.org/pos2015/agenda2030/> Acesso em: 20 jul.2017.

OWENS, K.A.; HALFACRE-HITCHCOCK, A. As green as we think? The case of the College of Charleston green building initiative. International Journal of Sustainability in Higher Education, v. 7, n. 2, p. 114-128, 2006.

SCHOLZ, R. W., MIEG, H. A, OSWALD, J. E. Transdisciplinarity in groundwater management: towards mutual learning of science and society. Water Air and Soil Pollution, v. 123, p. 477-87, 2000.

SHARP, L. Green campuses: the road from little victories to systemic transformation. International Journal of Sustainability in Higher Education, v. 3, n. 2, p. 128-45, 2002.

STEPHENS, J. C.; HERNANDEZ, M. E.; ROMÁN, M.; GRAHAM, A.C.; SCHOLZ, R. W. Higher education as a change agent for sustainability in different cultures and contexts. International Journal of Sustainability in Higher Education, v. 9, n. 3 p. 317-338, 2008.

STERLING, S. Higher education, sustainability, and the role of systemic learning. In Blaze Corcoran, P. B.; Wals, A. E. J. (Eds.). Higher Education and the Challenge of Sustainability: Problematics, Promise and Practice, Kluwer Academic Press, Dordrecht, 2005.

TAUCHEN, J. A. Um modelo de gestão ambiental para implantação em instituições de ensino superior. 2007. 149f. Dissertação (Mestrado em Engenharia do Ambiente) - Faculdade de Engenharia e Arquitetura da Universidade de Passo Fundo, Passo Fundo, 2007. Disponível em: < http://www.ppgeng.upf.br/images/stories/2005joeltauchen.pdf >. Acesso em: 12 mar. 2017.

TORMEY, R.; LIDDY, M.; MAGUIRE, H.; MCCLOAT, A. Working in the action/ research nexus for education for sustainable development: Two case studies from Ireland. International Journal of Sustainability in Higher Education, v. 9, n. 4 p. 428-440, 2008.

VAN DAM, R. Learning for sustainable development: is it possible within the established higher education structures? In: Holmberg, J.; Samuelsson, B. (Eds.). Drivers and Barriers for Implementing Sustainable Development in Higher Education, Unesco, Paris, 2006. 
VELAZQUEZ, L; MUNGUIA, N.; SANCHEZ, M. Deterring sustainability in higher education institutions. An ap.raisal of the factors which influence sustainability in higher education institutions. International Journal of Sustainability in Higher Education, v. 6, n. 4, p. 383-391, 2005.

ZITZKE, V. A. Educação Ambiental e Ecodesenvolvimento. Revista Eletrônica do Mestrado em Educação Ambiental. $\quad$ v. 9 , 2002. Disponível em: $<$ http://www.fisica.furg.br/mea/remea/vol9/a13art16.pdf> Acesso em 2 ago. 2017. 